\title{
МОРФОМЕТРИЧЕСКИЕ ХАРАКТЕРИСТИКИ ХВОИ ЕЛИ СИБИРСКОЙ В ЗОНЕ ВОЗДЕЙСТВИЯ КОМБИНАТА «СЕВЕРОНИКЕЛЬ»
}

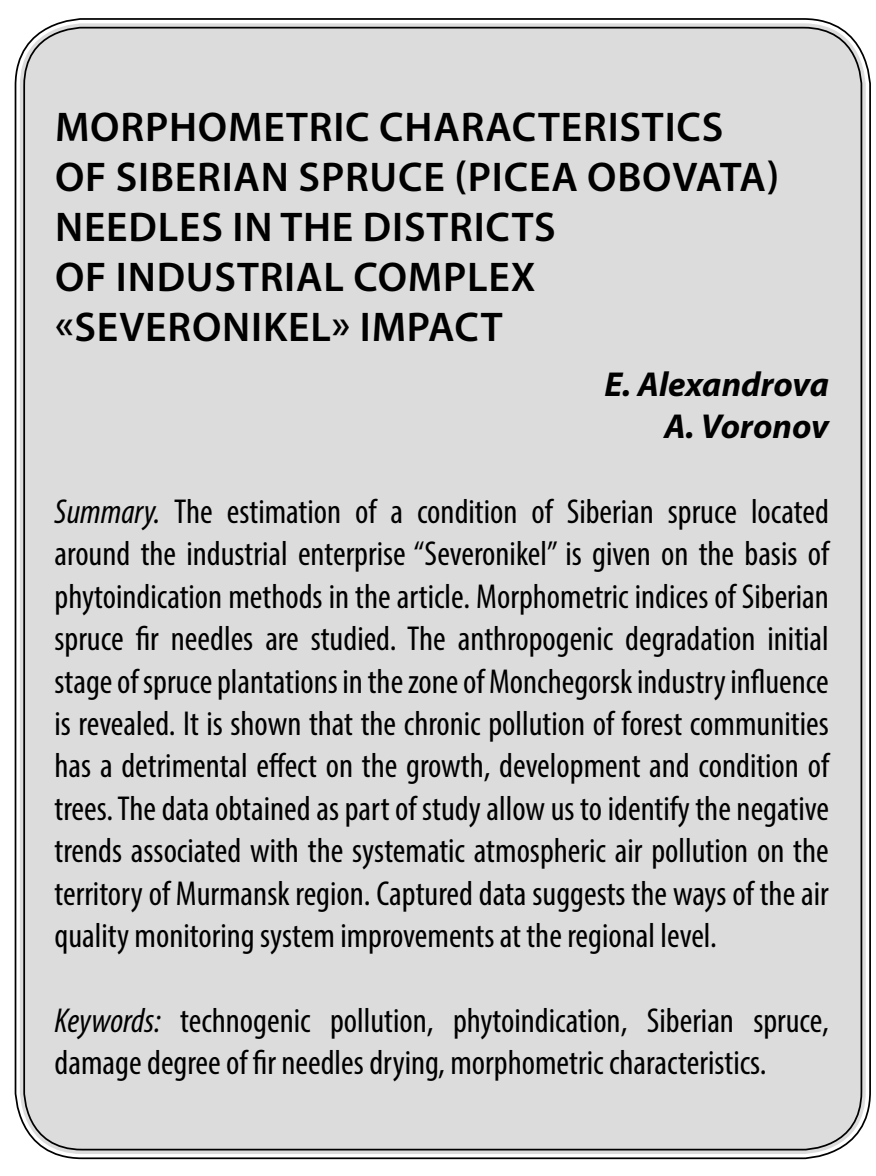

A ктивное развитие горнодобывающей и металлургической промышленности, сопровождающееся высокой степенью аэротехногенного загрязнения, обуславливает увеличение сбоев в гомеостатических механизмах компонентов биоценозов. При этом северные экосистемы подвергаются разрушительному воздействию в большей степени. Это связано с природно-климатическими условиями, которые обуславливают специфику северных экосистем: снижение устойчивости к загрязнению среды, уязвимость, замедление процессов самоочищения. В связи с этим актуальность приобретает систематическая оценка качественного состояния северных фитоценозов в условиях аэротехногенного загрязнения.

На Кольском полуострове находится предел в распространении хвойных растений, что обуславливает их особую чувствительность к дополнительным стрес-
Александрова Евгения Юрьевна

К.п.н., дочент, ФГБОУ ВО «Мурманский арктический государственный университет» (2. Мурманск) dzhessika_www@mail.ru

Воронов Алексей Александрович Главный специалист-эксперт, БалтийскоАрктическое межрегиональное управление Федеральной службы по надзору в сфере природопользования

Аннотация. В статье приведены результаты фитоиндикационной оценки состояния популяции ели сибирской, произрастающей вблизи промышленного комбината «Североникель». Изучены морфометрические показатели хвои ели сибирской, выявлена начальная стадия антропогенной дигрессии еловых насаждений в зоне влияния промышленности г. Мончегорска. Показано, что хроническое загрязнение лесных сообществ оказывает негативное влияние на рост, развитие и состояние деревьев. Данные, полученные в ходе исследования, позволяют выявить негативные тенденции, связанные с систематическим загрязнением атмосферного воздуха на территории Мурманской области, и предложить пути совершенствования системы контроля за качеством атмосферного воздуха на региональном уровне.

Ключевые слова: техногенное загрязнение, фитоиндикация, ель сибирская, степень повреждения и усыхания хвои, морфометрические характеристики.

совым факторам, и делает удобными объектами для экологических исследований. Визуально наблюдаемые изменения хвои (отклонения в развитии кроны, хлорозы и некрозы, снижение линейных и площадных параметров, общая сухая масса и др.) могут рассматриваться как информативные показатели аэротехногенного загрязнения.

Целью исследования являлось изучение морфометрических характеристик хвои ели сибирской в районе воздействия комбината «Североникель» (промышленная площадка АO «Кольская горно-металлургическая компания»).

Исследование проводилось в июле 2019 г.: определялась степень повреждения хвои ели сибирской в ходе дигрессионной сукцессии, проводился анализ морфометрических характеристик хвои как параметров ростовых 
процессов, осуществлялась оценка жизненного состояния и отклонений в архитектонике кроны ели сибирской в районе воздействия комбината «Североникель».

Образцы ели сибирской собирались на территории Мончегорского района Мурманской области, в тундровой зоне. Климат в данном районе умеренно суровый (средняя температура января составляет - $13^{\circ} \mathrm{C}$, сильные морозы бывают редко, господствуют северные, северо-восточные и северо-западные ветра, холодное короткое лето (средняя температур июня $+13^{\circ} \mathrm{C}$ ), суточный ход температур плавный, климат сильно влажный (годовое количество осадков - 410 мм, треть из которых - в виде снега). Снежный покров лежит более 200 дней в году. В лесной зоне преобладают маломощные подзолистые почвы. На юге и западе полуострова преобладают сосновые и елово-березовые леса [1].

Древесный ярус представлен елью, сосной и березой. Древостой, в основном, одноярусный, подлесок не выражен. В травянисто-кустарничковом ярусе доминируют водяника обоеполая (Empetrum hermaphroditum), черника миртолистная (Vaccinium mytillus), брусника обыкновенная (Vaccinium vitis-idaea). Также встречается голубика обыкновенная (Vaccinium uliginosum), вереск обыкновенный (Calluma vulgaris) и багульник болотный (Ledum palustre). Разнотравья и злаковых не много. Мохово-лишайниковый ярус сформирован зелеными мхами: плевроциум Шребера (Pleurozium schreberi), дикранум многоножковый (Dicranum polysetum), лишайниками: многочисленные представители из р. Cladonia - кладония дюймовая (Cladonia uncialis), кладония курчавая (Cladonia crispata), кладония рогатая (Cladonia cornuta), кладония стройная (Cladonia gracilis).

Исследования Т.В. Арсеньевой и Т.А.Сухаревой подтверждают, что основным источником загрязнения в исследуемом районе является крупнейший на Севере Европы медно-никелевый комбинат «Североникель». В составе выбросов в атмосферу обнаруживается медь, никель, кобальт, двуокись серы и пыль $[1,7]$.

Исследования, проводимые сотрудниками ПАБСИ КНЦ РАН, показали, что за последние несколько десятков лет наблюдалось снижение выбросов загрязняющих веществ со стороны комбината «Североникель». Однако концентрации металлов в снежном покрове, почве и осадках, по-прежнему, превышают допустимые нормативы.

Г.М. Кашулиной и Н.В. Салтан совместно с Кольским геологическим информационно-лабораторным центром показано, что в исследуемом районе наблюдается высокая ассимиляция растениями никеля, меди, марган- ца и цинка [3]. Более поздними работами данных авторов подтверждена многолетняя негативная тенденция накопления металлов в 2002-2012 гг. [6]. Отмечается, что отношение медианы концентраций металлов в хвое ели сибирской к фону в исследуемом районе варьирует от 0,5 (для марганца и цинка) до 32 (по никелю).

Объектом исследования являлась одна из наиболее распространенных пород региона - ель сибирская (Picea obovata Ledeb.), которая участвует в формировании древостоя северо-таежных ельников кустарничково-зеленомошных на северном пределе распространения хвойных растений.

В лесных сообществах Кольского Севера древесный ярус сформирован елью сибирской и березой пушистой, с участием ивы козьей и сосны обыкновенной. Доля ели сибирской в древесном ярусе не более 15\% по запасу, еловых лесов - 60-90\%. В составе подроста ель занимает подчиненное положение (не более $30 \%$ по плотности) [4].

Ель сибирская - вечнозеленое однодомное дерево высотой до 30 м с узкой конусовидной кроной и прямым стволом, имеет мелкие яйцевидно-цилиндрические шишки с выпуклыми широкими, закругленными по краю, цельнокрайними чешуями. Побеги покрыты короткими рыжими волосками, хвоя темно-зеленая, четерехгранная. Размер хвои варьирует в пределах 7-20 мм. Корневая система поверхностная, стержневой корень слабо развит, что обуславливает значительную ветровальность елей. В условиях Кольского полуострова из-за сильных ветров приобретает стланиковую форму, способна выдерживать вечную мерзлоту. Продолжительность жизни ели сибирской составляет 250-300 лет [1].

Северо-таежным еловым лесам Кольского Севера свойственна высокая степень разреженности и низкая плотность посадки. В связи с этим кроны елей опушены намного ниже, чем в южно-таежных и хвойно-широколиственных лесах [4].

Еловые леса Мурманской области с преобладанием ели сибирской занимают около 38\% всего лесопокрытия. Чистые еловые насаждения, как правило, не встречаются. Семенной зрелости ель в северных насаждениях достигает в возрасте 50-70 лет, на вырубках и опушках - в 30-40 лет. Ель сибирская предпочитает влажные почвы, не выносит иссушения, отличается слабой дымои газоустройчивостью.

Ухудшение условий произрастания усиливает защитную реакцию ели сибирской, в то же время она обладает более узкой адаптивной амплитудой, чем другие хвойные. В связи с этим ель сибирская более чувствительна 


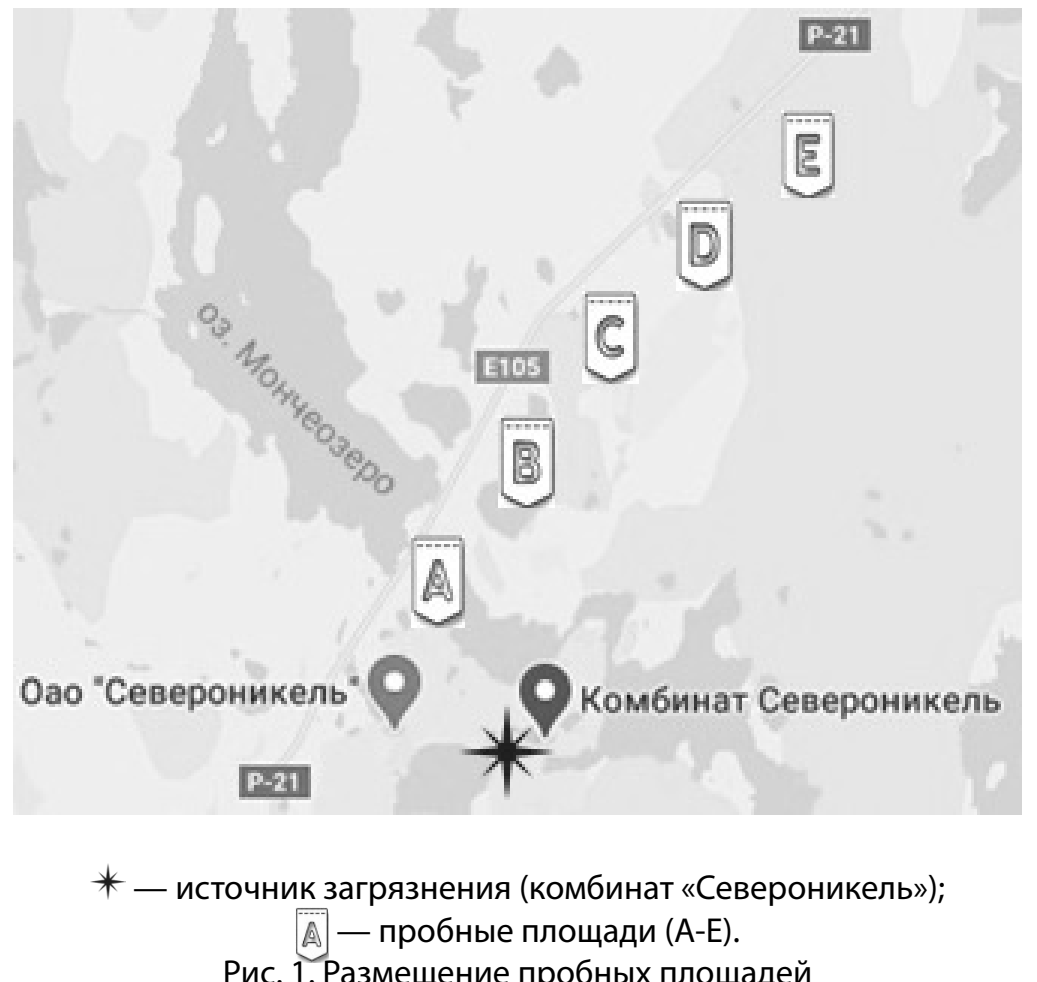

Рис. 1. Размещение пробных площадей

к промышленному загрязнению среды, чем, например, сосна обыкновенная [1].

\section{Материалы и метолы}

Для организации исследования было заложено пять пробных площадей (A-E) в Мончегорском районе по оси факела выбросов комбината «Североникель» с учетом преобладающего северо-восточного направления ветра (рис. 1).

Пробные площади были заложены на удалении 2,5 км друг от друга по принципу зонирования территории по комплексному показателю загрязнения атмосферного воздуха в импактной (0-5 км) и буферной (7,5-12,5 км) зонах.

Для каждой пробной площади устанавливалась стадия дигрессионной сукцессии: стадия техногенной пустоши - 0-2 км, стадия техногенного редколесья (АB) - 2,5-5 км, стадия затухающей дефолиации (C-D) 7,5-10 км, стадия интенсивной дефолиации (E) - 12,5 км. Также были выбраны зоны слабого загрязнения, приближенные к фоновой: (F) - вблизи оз. Чайка (в лесополосе, 8 км от Восточно-Объездной дороги) и (G) - оз. Лапоть (Кольский Район, 16-й км Серебрянского шоссе).

На каждой пробной площади анализировали 20 деревьев. Отбор хвои производился из верхней трети кроны в вегетационный период. Хвоя сортировалась по возрастным группам. Морфометрическое обследование включало замеры длины и ширины хвои, оценку степени повреждений ассимилирующих органов (хлорозы, некрозы). Длина хвои различных возрастных классов измерялась с точностью до 1 мм. Также определялась максимальная продолжительность жизни хвои и рассчитывалась общая сферическая поверхность хвои по А.И. Уткину [9]. Класс повреждения хвои устанавливались по Т.А. Сухаревой: неповрежденная (1 класс, 0\%), слабо-поврежденная (2 класс, до 25\%), умеренно-поврежденная (3 класс, до 75\%), сильно-поврежденная (4 класс, более 75\%) [7].

Отклонения в архитектонике кроны ели сибирской определяли визуально. Оценка категории жизненного состояния хвойных растений проводилась по Е.Г. Мозолевской: без признаков ослабления, ослабленные, сильно ослабленные, усыхающие, сухостой текущего года, сухостой прошлый лет. Исследуемым деревьям присваивался класс устойчивости: 1 класс - биологически устойчивые, 2 класс - нарушенная устойчивость, 3 класс - утратившие устойчивость [5].

\section{Полученные результаты и их обсужАение}

Хвоя ели сибирской в фоновых условиях имеет продолжительность жизни 8-13 лет. Количество возрастных классов хвои зависит от ветвления побега, обычно не превышает 5 . 
Таблица 1. Морфометрические характеристики хвои ели сибирской в зоне воздействия комбината (для побегов 1-2 года)

\begin{tabular}{|c|c|c|c|c|c|c|}
\hline \multicolumn{2}{|c|}{ Параметр / Пробная площадь } & A & B & C & D & E \\
\hline \multirow{2}{*}{$\begin{array}{l}\text { Длина хвои } \\
\text { (фон: 10-12 мм) }\end{array}$} & Диапазон длины, мм & $8-10$ & $9-11$ & $10-11$ & $10-12$ & $12-14$ \\
\hline & Медиана/фон & 0,82 & 0,91 & 0,95 & 1,0 & 1,18 \\
\hline \multirow{2}{*}{$\begin{array}{l}\text { Общая поверхность хвои, } \\
\text { мм² }^{2}\end{array}$} & $\begin{array}{l}\text { Медиана общей } \\
\text { поверхности }\end{array}$ & 20,63 & 20,08 & 29,78 & 34,25 & 44,84 \\
\hline & Медиана/фон & 0,57 & 0,55 & 0,82 & 0,94 & 1,24 \\
\hline \multirow{2}{*}{$\begin{array}{l}\text { Повреждение хвои (фон: } \\
\text { 15\%) }\end{array}$} & Медина повреждения,\% & 78,2 & 68,2 & 59,1 & 46,6 & 24,0 \\
\hline & Медиана/фон & 5,21 & 4,54 & 3,94 & 3,11 & 1,6 \\
\hline
\end{tabular}

Таблица 2. Жизнеспособность ели сибирской (\%)

\begin{tabular}{|c|c|c|c|c|c|c|}
\hline $\begin{array}{l}\text { Пробная пло- } \\
\text { щадь }\end{array}$ & $\begin{array}{l}\text { без признаков осла- } \\
\text { бления }\end{array}$ & ослабленные & $\begin{array}{l}\text { сильно осла- } \\
\text { бленные }\end{array}$ & усыхающие & $\begin{array}{l}\text { сухостой теку- } \\
\text { щего года }\end{array}$ & $\begin{array}{l}\text { сухостой про- } \\
\text { шлый лет }\end{array}$ \\
\hline A & $0 \%$ & $0 \%$ & $79,20 \%$ & $20,80 \%$ & $0 \%$ & $0 \%$ \\
\hline B & $0 \%$ & $6 \%$ & $90,40 \%$ & $3,20 \%$ & $0,40 \%$ & $0 \%$ \\
\hline C & $22,80 \%$ & $58,40 \%$ & $16,80 \%$ & $0,80 \%$ & $0,40 \%$ & $0 \%$ \\
\hline D & $26,40 \%$ & $64 \%$ & $8 \%$ & $0,80 \%$ & $0,40 \%$ & $0,40 \%$ \\
\hline E & $30 \%$ & $63,20 \%$ & $6 \%$ & $0,40 \%$ & $0,40 \%$ & $0 \%$ \\
\hline $\mathrm{F}_{\phi о н}$ & $88,80 \%$ & $10 \%$ & $1,20 \%$ & $0 \%$ & $0 \%$ & $0 \%$ \\
\hline $\mathrm{G}_{\text {фон }}$ & $85,20 \%$ & $12,80 \%$ & $2 \%$ & $0 \%$ & $0 \%$ & $0 \%$ \\
\hline
\end{tabular}

Максимальных размеров хвоя достигает на побегах I-II порядков, минимальная - V порядка. В фоновых условиях средний возраст хвои ели сибирской

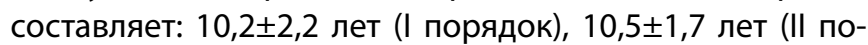

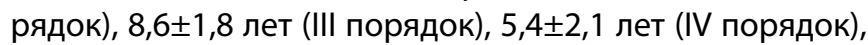
1,8 $\pm 0,6$ лет ( $V$ порядок). Большая часть хвои не обнаруживает признаков повреждения, доля хлорозов и некрозов не превышает 15\%. Наиболее поврежденной оказывается хвоя последних лет жизни (старовозрастная). На молодой хвое не более $2 \%$ повреждений.

Средняя длина хвои в фоновых условиях составляет $11,4 \pm 0,05$ мм (минимальная длина - не более 3 мм, максимальная - 20 мм). Длина и общая поверхность хвои возрастает по мере старения побега.

В ходе деградационной сукцессии зафиксирована нелинейная изменчивость морфометрических характеристик хвои ели сибирской. На начальной стадии дигрессии (интенсификация дефолиации) медиана общей поверхности (44,84 мм²) и длины хвои (12-14 мм) больше, чем в фоновой зоне (36,28 мм² и 10-12 мм). Это обусловлено увеличением подвижности минеральных эле- ментов в почвенном покрове. На последующих стадиях (стадия затухающей дефолиации и стадия техногенного редколесья) отмечается ухудшение морфометрических характеристик: соотношение медианы к фоновому значению постепенно уменьшается (таблица 1).

Как показало исследование, вблизи источника загрязнения (А) степень повреждения хвои достигает 78,2\%, хвоя отнесена к 4-му класса повреждения. Здесь преобладает однолетняя хвоя с длиной 8-10 мм, в то время как в фоновой зоне ее размер составляет 10-12 мм. В зоне интенсификации дефолиации (Е) - 12-14 мм (2 класс повреждения), в зоне затухающей дефолиации и редколесья (B-D) - 9-12 мм (3 класс повреждения).

В условиях сильного аэротехногенного загрязнения отмечено снижение длины и общей поверхности хвои по сравнению с фоном. Для ширины такая зависимость проявляется не во всех случаях: в ряде проб ширина хвои приближается к фоновым значениям.

Сравнительный анализ площадей А-В показывает, что при значительном различии в размерах хвои, пло- 
щади их поверхностей могут быть близкими по значениям. Это подтверждает результаты более ранних морфометрических исследований [2]. Исходя из этого, интегральные показатели для оценки хвои более удобны в экологических исследованиях. Также отмечено, что наиболее информативны данные по хвое первого года жизни, так как с возрастом в хвое формируется адаптация биосинтетических процессов к условиям среды.

Как показало исследование, в ходе интенсивной дефолиации продолжительность жизни хвои не отличается от фоновых значений. Для стадии затухающей дефолиации и техногенного редколесья этот показатель снижается (уменьшается число возрастных классов до 2-х, снижается порядок ветвления побегов до IV).

На расстояния 0-2,0 км от источника загрязнения наблюдается стадия техногенной пустоши: хвойные растения отсутствуют. На пробных площадях A-B (2,5-5 км, стадия техногенного редколесья) большая часть растений отнесена к категории «утратившие устойчивость», на пробных площадях C-E (7,5-12,5 км, стадия затухающей и интенсивной дефолиации) отмечается «нарушенная устойчивость». Фоновые объекты (F-G) отнесены к классу «биологически устойчивых».

Анализ состояния хвойных растений на исследуемой территории свидетельствует о том, что преобладающие средневозрастные деревья имеют значительные различия в жизнеспособности при удалении от источника загрязнения (таблица 2). Полученные данные подтверждают результаты ранее проводимых нами исследований (2018 г.) с использованием ели сибирской [10].

Исходя из классификации жизненных форм, ель сибирская относится к одноствольным деревьям. В тоже время обнаруживаются и немногоствольные формы (2-3 ствола, раздвоение верхней части кроны от центра или на высоте до 0,5-1,3 м): (B) - 13\%, (C) - 19\%, (D) - 14\%. Это обусловлено задержкой роста главной оси и раннего развития побегов из боковых (спящих) почек. При исследовании архтектоники ели сибирской на расстоянии до 7,5 км от источника загрязнения были обнаружены следующие отклонения: 1) ажурность (сквозистость) кроны - крона средней плотности с 25-50\% просветов; 2) отклонения в пропорциях (нарушение пирамидальной формы кроны, непропорциональный рост побегов); 3) неравномерность отмирания нижних побегов до 0,5 м высоты (по одной из сторон главной оси), отмирание побегов по главной оси за исключением верхушки, отмирание центральной части кроны (по типу «песочные часы»); 4) нарушение ортотропного роста главной оси (искривление верхушки кроны, изменение угла роста); 5) слабая опушенность подроста, малорослость (до 2 м) деревьев (на расстоянии до 7,5 км от комбината «Североникель»).

\section{Зак^ючение}

Аэротехногенное загрязнение в Мончегорском районе оказывает существенное влияние на все компоненты лесной растительности: происходит отмирание древостоя, разрушение нижних ярусов и внеярусной растительности.

При этом региональное загрязнение коррелирует с ответной реакцией биоценозов на техногенное загрязнение. Так, вблизи источника загрязнения (0-2,0 км) хвойные растения не произрастают вообще, наблюдается высокая степень деградации лесного биоценоза (стадия техногенной пустоши).

В условиях серьезного аэротехногенного загрязнения со стороны комбината «Североникель» морфометрические характеристики хвои ели значительно отклоняются от естественных пределов: уменьшаются размеры хвои, сокращается продолжительность жизни хвои, увеличивается густота побегов. Сильное атмосферное загрязнение усиливает дехромацию и дефолиацию кроны ели, у подроста они выражены слабее. Хлорозы приурочены, в основном, к верхушечной части хвоинок, также обнаруживаются микроскопические пятна некрозов из-за проникновения загрязняющих веществ через устьица и разрушенную кутикулу. Хлорозы отсутствуют у одно- и двухлетних побегов.

В ходе дигрессионной сукцессии зафиксирована нелинейная изменчивость морфометрических характеристик хвои ели сибирской. На территориях с интенсивной дефолиацией длина и общая сферическая поверхность хвои больше, чем в фоновых условиях (хвоя крупнее). На последующих стадиях дигрессии наблюдается уменьшение длины и общей сферической поверхности. Наименьшую общую сферическую поверхность имеет хвоя текущего года и однолетняя хвоя на стадии техногенного редколесья.

На стадии интенсивной дефолиации обнаруживается увеличение длины и общей сферической поверхности хвои, которое обусловлено повышенным содержанием в ассимилирующих органах элементов питания и снижением количества фенолов. Как отмечает Т. А. Сухарева [7], при снижении концентрации элементов питания (магния и кальция) до уровня дефицита наблюдается обратная тенденция, когда размеры хвои уменьшаются, усиливается синтез вторичных метаболитов - фенолов (на стадии техногенного редколесья и затухающей дефолиации). 


\section{ЛИТЕРАТУРА}

1. Арсеньева Т.В., Чавчавадзе Е. С. Эколого-анатомические аспекты изменчивости древесины сосновых из промышленных районов Европейского Севера. СПб: Наука, 2001, 109 c.

2. Есякова 0.А., Степень Р. А. Индикация загрязнения атмосферы Красноярска по морфометрическим и химическим показателям хвои ели сибирской // Химия растительного сырья, 2008, № 1, с. 143-148.

3. Кашулина Г.М., Салтан Н. В. Химический состав растений в экстремальных условиях локальной зоны комбината «Североникель», Апатиты: КНЦ РАН, 2008, 239 c.

4. Катютин П.Н., Ставрова Н. И. Взаимосвязь возраста и величины диаметра особей в ценопопуляциях ели сибирской на разных стадиях послепожарных сукцессий // Известия Самарского научного центра РАН, 2012, т. 14, № 1(5), с. 1257-1260.

5. Мозолевская, Е. Г. Первичные и интегральные показатели состояния насаждений, используемые при мониторинге // Лесной вестник, 2000 , № 6, с. 65-67.

6. Салтан Н. В. Динамика содержания тяжелых металлов в ассимилирующих органах растений локальной зоны воздействия комбината «Североникель» // Вестник МГТУ, 2013, т. 16, № 4, с. 793-802.

7. Сухарева Т. А. Химический состав и морфометрические характеристики хвои ели сибирской в условиях воздушного промышленного загрязнения. Автореферат дис. на соиск. учен. степ.к.б.н. Петрозаводск, 2004, 32 с.

8. Сухарева Т.А., Лукина Н. В. Химический состав и морфометрические характеристики хвои ели сибирской на Кольском полуострове в процессе деградационной сукцессии лесов // Лесоведение, 2004, № 2, с. 36-43.

9. Уткин А. И. Площадь поверхности лесных растений: сущность, параметры, использование. М.: Наука, 2008, 292 с.

10. AleksandrovaE. Yu.,Trotsenko A. A.,Minchenok E. E.,Kovaleva T. 0.,Katansky A. A. Bioindicationpotentialofconifersforenvironmentalassessment//AGRITECH-II-2019: IOP Conference Series: Earth and Environmenat Science. 2020. Vol. 421(1). P. 011001 (1-10). D0I: 10.1088/1755-1315/421/2/ 022036.

( ) Александрова Евгения Юрьевна (dzhessika_www@mail.ru ), Воронов Алексей Александрович. Журнал «Современная наука: актуальные проблемы теории и практики»

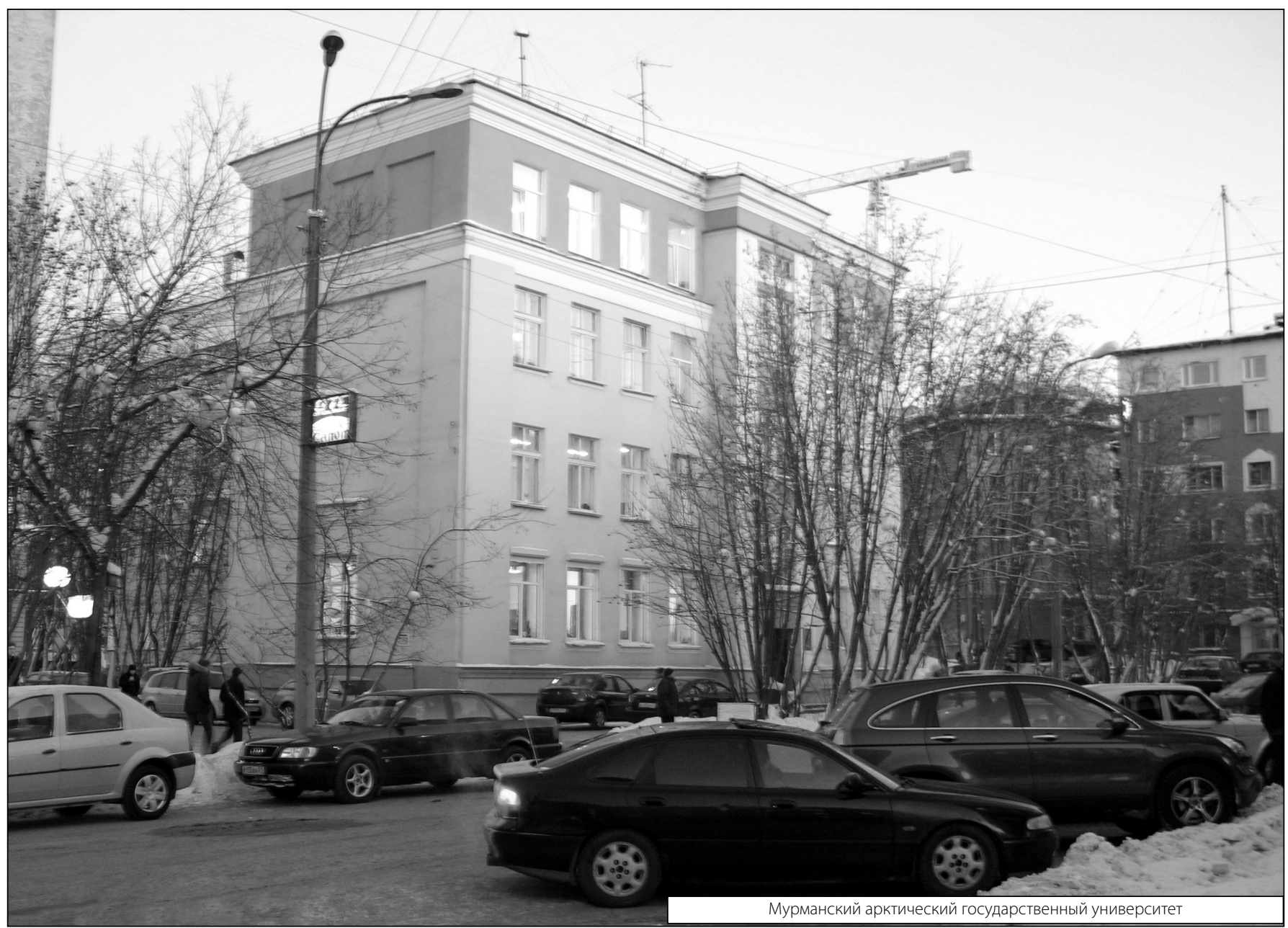

